\title{
Erratum to: Assessing dilute acid pretreatment of different lignocellulosic biomasses for enhanced sugar production
}

\author{
Zhanying Zhang • Tony Vancov - Shane McIntosh • Biswajit Basu • \\ Arvinal Lali • Guangren Qian · Philip Hobson - William O. S. Doherty
}

Published online: 12 June 2017

(C) Springer Science+Business Media B.V. 2017

Erratum to: Cellulose (2016) 23:3771-3783 DOI 10.1007/s10570-016-1043-6

In the original publication of the article, one of the coauthor names Shane McIntosh was spelled incorrectly as Shane Mackintosh. It has been updated in this erratum.

The online version of the original article can be found under doi:10.1007/s10570-016-1043-6.

Z. Zhang $(\bowtie) \cdot$ P. Hobson · W. O. S. Doherty

Centre for Tropical Crops and Biocommodities,

Queensland University of Technology, GPO Box 2432, 2

George St, Brisbane, QLD 4001, Australia

e-mail: jan.zhang@qut.edu.au

T. Vancov $\cdot$ S. McIntosh

NSW Department of Primary Industries, Wollongbar

Primary Industries Institute, Wollongbar, Australia

B. Basu

DBT-IOC Centre for Advanced Research on Bioenergy,

R\&D Centre, Indian Oil Corporation, Faridabad, India

A. Lali

DBT-ICT Centre for Energy Biosciences, Institute of

Chemical Technology, Mumbai, India

G. Qian

School of Environmental and Chemical Engineering,

Shanghai University, Shanghai, China 